\title{
UNA MIRADA REGIONAL A LA EXTENSIÓN UNIVERSITARIA
}

Héctor Luis Morales* 


\section{RESUMEN}

Este artículo presenta una mirada ambigua desde las regiones, y especialmente desde la Universidad de La Serena, acerca de la extensión universitaria. Se reivindica, por una parte, el valor del patrimonio y de la historia local como un recurso valioso y, a la vez, se expresa una queja contra el paradigma o prejuicio que lleva a valorar únicamente lo que viene desde el centro político, cultural y económico del país. Una de las proposiciones es la necesidad de producir sinergias entre riquezas complementarias para potenciar los valores que emergen de las universidades de todo el territorio. Las universidades regionales producen materia prima cultural y ésta adquiere su plusvalía (y su madurez y triunfo) en centros nacionales y extranjeros. Nuevas políticas y acciones institucionales podrían crear una nueva relación más cooperativa y menos competitiva entre las universidades de todo el país.

\section{ABSTRACT}

This paper presents an ambiguous examination from the viewpoint of the regions of university outreach activities especially from the Universidad de La Serena. On the one hand, it vindicates the value of local heritage and history as a valuable resource while at the same time it complains against the paradigm or prejudice that leads to ascribing value exclusively to what originates from the political, cultural and economic center of the country. One of the proposals is the need to produce synergies between supplementary assets to enhance the values that emerge from the universities throughout the country. Regional universities produce cultural raw material and this increases in value (and matures and triumphs) in national and foreign centers. New policies and institutional actions could create a more cooperative and less competitive relationship among the universities throughout the entire country. 


\section{UNA MIRADA REGIONAL A LA EXTENSIÓN UNIVERSITARIA}

Introducción

Se cuestiona muy fuertemente, hoy en día, el sentido clásico de la extensión como una función dentro del quehacer académico, especialmente en las nuevas empresas educativas. En este sentido clásico, según Ortega y Gasset, la universidad tenía entre sus funciones esta actividad como un nexo con la sociedad, como una expresión de compromiso ideológico, cultural y científico. En la actualidad se entiende que, además de la cultura artística, se incluyen la asistencia técnica y la capacitación, siendo estas últimas una fuente de ingentes ingresos, situación que no se da con las artes. Queda pendiente analizar, en otro contexto, el significado actual de la extensión universitaria, apostando, desde ya, que ésta existe, que es importante y que debe ser asumida con mayor responsabilidad en toda la institucionalidad universitaria.

Por otra parte, surgen preguntas, igualmente, acerca del sentido de lo "regional", palabra que se torna ambigua cuando se aplica a realidades muy diversas como, por ejemplo, la "región sudamericana" o la "región andina". En nuestro caso chileno entendemos que la región es una figura que ha instaurado el Estado para facilitar la administración del país y que, posteriormente, se ha dado un proceso y un impulso para que los ciudadanos de éstas asuman su identidad y su desarrollo. Queda igualmente pendiente la discusión acerca del sentido teórico de este concepto. Pero se puede estar seguro que, de todas maneras, estamos clara y numéricamente clasificados en mapas, censos y balances -públicos y privados-, útiles especialmente para los administradores nacionales -públicos y privados-, quienes recitan 
autísticamente los numerales: la "cuarta", la "segunda", la "décima". Como ciudadanos de un país es preciso que se limpie el concepto de que hay zonas o regiones de primera, de segunda o de otras categorías, pues, en la práctica, la realidad del centralismo impone una tal diferenciación para las oportunidades, los concursos y las expectativas de desarrollo, incluida la vida universitaria.

El peso y valor de la historia y del patrimonio regional y local

Una primera reflexión surge acerca del reconocimiento de la historia y del patrimonio local y regional en los cuales se encuentran las llamadas "universidades regionales". Algunas de éstas han sido creadas por un impulso propio de sus ciudadanos o de instituciones importantes de la zona. Se puede citar el ejemplo de la Universidad de Concepción; de la Universidad Austral de Chile, en Valdivia, o de la Universidad Técnica Federico Santa María, en Valparaíso. La Universidad de La Serena remonta sus orígenes a la actividad pionera de Ignacio Domeyko con la primera enseñanza de la minería, lo que posteriormente derivó hacia la Escuela de Minas (experiencia relativamente parecida a la de Copiapó), a la cual se suma la de las Escuelas Normales de Copiapó y de La Serena. En estos casos se aprecia el importante esfuerzo de los ciudadanos para crear y desarrollar instituciones, que valorizan y respetan, y para fortalecer una tradición que sigue hasta nuestros días ${ }^{1}$.

Este acervo local y regional, de carácter histórico, constituye una riqueza que vale por sí misma, más allá de toda comparación o referencia "centro-periferia" y es, por lo mismo, base de una autonomía de identidad cultural que debe ser reconocida no sólo por los responsables universitarios locales, sino por todo lo que constituye el aparato estatal nacional de la educación y de la cultura, especialmente en el caso de programas o de intervenciones que se aplican a todo el país. El peso y valor del patrimonio regional debiera ser un referente

1 En La Serena existe el Centro de Ex Alumnos del Liceo Gregorio Cordovez, institución que se precia de haber sido fundada por don Bernardo O'Higgins y que mantiene en activa relación a sus asociados, entre los cuales se encuentran prominentes escritores, jueces, políticos y ciudadanos. La actividad musical del profesor Jorge Peña Hen está viva hasta hoy en quienes participaron en sus coros y orquestas, y su iniciativa de las orquestas juveniles se replica nacional e internacionalmente. 
fundamental en todo el quehacer cultural, educativo y universitario, para lo cual es preciso que este patrimonio sea estudiado, reconocido y reasimilado por las nuevas generaciones. La globalización fortalecerá este reconocimiento y valorización en la medida en que sea capaz de transmitirse a dimensiones amplias, pues en ese ámbito el valor de lo auténtico, de lo propio, es calibrado, medido y reconocido. Se trata, por ejemplo, de la experiencia gastronómica, de las bellas artes, de las artesanías y de la capacidad científica, y es tarea de la extensión descubrir y dinamizar el potencial de este patrimonio.

\section{La inercia de las instituciones y de la burocracia}

La extensión universitaria se desarrolla en el marco de las universidades regionales, especialmente de las derivadas de las universidades de Chile y Técnica del Estado. En éstas se debe reconocer una inercia institucional y de carácter burocrático que ha sido heredada de sus instituciones maternas: extensión centrada en los clásicos programas de carácter artístico (conciertos, exposiciones) o de carácter formativo (temporadas de verano), o en los trabajos estudiantiles de gran impacto social. Muchas de estas actividades son irrepetibles, no interesan a la gente y hay muchos problemas en obtener financiamiento para su producción. Esta inercia ha sido superada en muchos casos, y se han buscado nuevos caminos en programas innovadores a través de trabajos con grupos etarios, especialmente niños o adultos mayores, o, en otros casos, en proyectos de perfeccionamiento profesional, como la formación de líderes sociales, por ejemplo². Hay universidades que han centrado sus actividades de extensión en la asistencia técnica a medianos o pequeños empresarios de distintos sectores (agricultores, pescadores, mineros, artesanos, mecánicos), o a un trabajo prioritario con grupos étnicos o de otras nacionalidades. Junto a la inercia de los modelos antiguos se tiene también el peso de una burocracia que pesa en el desarrollo de los programas de extensión en las universidades

2 La Universidad de La Serena ha desarrollado desde su fundación reciente, en 1981, nuevos y numerosos programas y actividades de extensión cultural, variando el estilo y la temática de los antiguos. Entre éstos, el Programa del Adulto Mayor, que realiza ciclos de conferencias, talleres, cursos de monitores y diplomados en torno al tema general de gerontología. Por otra parte, desde hace seis años se lleva a cabo cada verano la Universidad de los Niños, una actividad integral de teatro, música y artes plásticas. Otros proyectos han centrado su atención en la formación de líderes sociales, sindicales y guías de turismo, obteniendo una amplia respuesta de los interesados. 
estatales, especialmente en las regionales, pues los estatutos y los procedimientos suelen cerrar el camino a experiencias innovadoras, a lo que se une la dificultad, en algunas regiones, para contar con el apoyo financiero de empresas, las que suelen radicar y tributar en la capital. El peso de la burocracia se refleja en las asignaciones presupuestarias, que no cambian sus esquemas de distribución de recursos. Para la mayoría de las universidades el presupuesto asignado a las direcciones de extensión fluctúa entre el 1 y el 2\%. De allí que es preciso trabajar con un esquema de evolución lenta y de cambios sencillos y progresivos, ambiente en el que no se concibe una reingeniería frontal.

Los límites de la escala y de las formas de dependencia

Siguiendo con las reflexiones iniciadas en los puntos anteriores, llegamos al terreno de lo posible y de las barreras que aparecen en la realización de sueños, pues cuando éstos surgen nos levantan hacia una estratósfera cultural en la que creemos que podemos transformarnos, de un día para otro, en un hito cultural de relevancia mundial. La verdad es que las llamadas "regiones" pueden ser terreno de siembras a futuro, pero no será en estas zonas donde emerjan los talentos o encuentren sus clímax de desarrollo. Pienso que Gabriela Mistral, Pablo Neruda o Claudio Arrau llevaron al mundo el germen y el recuerdo de sus tierras, sus valles, sus bosques y sus lluvias. Pero la madurez y el reconocimiento lo alcanzaron en Santiago, París, Berlín o Estocolmo. El sentido de la escala nos dimensiona a una especie de posición o "nicho" en esta carrera creativa, en la cual somos dependientes no sólo de las oportunidades de financiamiento, sino también de las oportunidades de madurez, a menos que luchemos por crear, en nuestros espacios o nichos, mayores oportunidades de crecimiento, objetivo que se podría lograr si se buscara una mayor concentración de masas críticas de artistas, creadores y administradores. Eso podría llevar a un sitial más promisorio a ciudades o regiones en las que una actividad cultural o artística se desarrollara como un cluster, al decir de los planificadores de desarrollo económico que buscan configurar encadenamientos de una diversidad de actores en torno a una actividad destacada. Estos encadenamientos debieran ser construidos sobre la base de una actividad original, rica en promesas. Puede ser la música, las artes plásticas, las artesanías, la gastronomía u otra cualquiera. En 
la zona de Pátzcuaro, en el Estado de Michoacán, en México, el noble obispo Vasco de Quiroga enseñó, en los albores de la Colonia, artesanías diversas a los pueblos originarios, dejándolos hasta hoy con una riqueza cultural que les permite no sólo vivir, sino mostrarse al mundo en un verdadero cluster, en que el turismo sirve como catalizador de la actividad.

Los nichos de creatividad y desarrollo

Cabe referirse ahora a los espacios propios y a los potenciales caminos para una extensión universitaria en las regiones. Basado en mi propia experiencia, de cerca de diez años, puedo decir que, en las regiones, contemplamos desde lejos, y a veces nos caen de visita, las muestras de una actividad cultural "de prestigio", aquella de las grandes universidades de la capital. Por ejemplo, en una ocasión el Ballet Nacional de la Universidad de Chile fue invitado a participar en una presentación de "Carmina Burana". La orquesta y el coro eran de la Universidad de La Serena, el director y los solistas de Santiago, y se realizó una sola presentación del conjunto completo. No había un local adecuado en la ciudad (el que fuera el Teatro Nacional fue demolido a fines de los años ochenta, pues era más redituable vender las maderas de pino oregón y usar el sitio como estacionamiento) y la presentación fue en un estadio techado. Asistieron cerca de 4.000 personas al concierto y los ingresos cubrieron sólo el 60\% de los costos.

A estas amargas consideraciones debemos agregar, enseguida, la pregunta de cuáles podrían ser nuestros "nichos" de operación, nuestros espacios de creatividad y cómo podríamos dar un salto cualitativo y cuantitativo con nuestros actores y nuestros recursos culturales y patrimoniales. ¿O estamos condenamos a ser simplemente productores de materia prima, de commodities culturales?

Por esto, urge un profundo examen de muchas categorías, paradigmas o, más simplemente, prejuicios acerca del verdadero valor comparativo de los programas culturales universitarios. En la práctica se presume que lo capitalino es por esencia mejor, en circunstancias que no siempre es así, o que esta comparación podría mejorar si se impusieran criterios y políticas de cooperación y sinergia entre las instituciones. 
En algún momento, la Universidad de Chile marcaba con su presencia (su cultura organizacional y su ethos) una acción cultural a través del país. Dondequiera que fuese, era su estilo y sello el que dejaba en sus acciones, sin necesariamente comparar o discriminar. La derivación de las sedes en universidades regionales causó una ruptura filial y, desde entonces, más que relaciones de cooperación han sido de competencia desigual, perdiendo la propia alma mater esa dimensión de creatividad en un espacio ampliado, real, en lo nacional. Sin pretender reconstruir artificialmente el pasado, hay algo que falta en la sinergia nacional de la cultura: el aprovechamiento integrado de las riquezas propias y complementarias, la búsqueda de una política nacional cultural en que las universidades no sean consideradas sólo como buzones de correos y en la que los recursos vayan asociados con indicadores objetivos de desarrollo cultural propio. Las universidades reciben actualmente un aporte fiscal por estudiantes de altos puntajes matriculados, pero no existe un aporte fiscal directo por egresados de altos méritos. En vez de ser el pago a una promesa debería haber un pago "al producto": músicos, literatos, artistas plásticos, artistas o directores de danza, teatro o cine, guionistas destacados a través de obras que hayan merecido un demostrado reconocimiento público. Esos incentivos provocarían un movimiento de mayor consagración y compromiso institucional, para llevar a sus estudiantes hacia niveles de calidad y prestigio, y poniendo de manifiesto la capacidad que las universidades tienen en regiones.

\section{Conclusiones}

Nuestra mirada regional a la extensión universitaria en general, y no sólo cultural artística, es ambigua, pues junto con valorar la riqueza de lo propio, expresa una queja amarga de la dependencia y marginalidad respecto de un centro que domina todo, centrado en la lógica del desarrollo económico, y que lo proyecta hacia las otras dimensiones de la vida social. Quisiéramos ser como las universidades centrales del país y, a pesar de esta ambigüedad, estamos dando pasos en pequeños nichos de creatividad desde los cuales queremos emerger. Esto demuestra que se puede ser innovador, producir materiales nuevos que van a las radios, a sitios de Internet. Muchos ejemplos podrían ilustrar estas aseveraciones. Hay también el llamado a que la universidad sea más abierta y sincera en sus relaciones con la sociedad 
actual: con la global, la nacional, la regional y local. No basta formar profesionales eficientes y competitivos. Urge atender a su formación humana, social y responsable, de sus familias y comunidades. Se debe marcar una presencia con respuestas a los problemas que se plantean en todos los planos del devenir humano: político, ético, empresarial, de relaciones internacionales y de conflictos ambientales, entre otros. Para ello, la competencia debe convertirse en colaboración, sinergia, apoyo complementario, reconocimiento de valores y de diferencias. La imagen de las instituciones universitarias debe crecer en la capacidad de ser maestra y faro y no solamente fábrica de operadores. Una tarea que no es fácil, pero posible en el contexto actual, si las instituciones logran concertarse en un nuevo pacto nacional a propósito del desarrollo cultural ${ }^{3}$.

Señalo, finalmente, una serie de estrategias y medidas que las universidades regionales podrían aplicar en su organización o estructura y en sus planes de desarrollo:

1. Sería preciso estudiar la conveniencia de la integración de programas, proyectos o actividades de extensión cultural, extensión académica, capacitación y asistencia técnica (en su conjunto o algunos de ellos) en una estructura de mayor cohesión institucional interna, por ejemplo, en el nivel de una vicerrectoría, forma que han adoptado algunas universidades chilenas.

2. Es necesario que las actividades de extensión, en su sentido amplio, sean reconocidas como una parte del quehacer académico y del horario de profesores y ayudantes, del mismo modo que se hace con la docencia e investigación.

3 La fortaleza en las redes nacionales o internacionales puede ser aprovechada en beneficio de un mejoramiento creativo y de encadenamiento de potenciales culturales entre regiones, y de éstas con los centros capitales. Los trabajos y escritos surgidos del Programa Universidades - Gobiernos Regionales, desde 1996 a 2003, dan cuenta de un esfuerzo de cooperación en el ámbito nacional. Del mismo modo, redes internacionales, como es el caso del Grupo Coimbra, de la Red Columbus o del Centro Interuniversitario de Desarrollo (CINDA), pueden apoyar el desarrollo de sinergias culturales. Cabe señalar, igualmente, que es preciso que en el ámbito de estas redes se valorice el aporte de las actividades de extensión a la carrera académica de los profesores, de tal manera que se reconozcan el tiempo y el esfuerzo en su currículum y en su carga horaria y que, por otra parte, los académicos aprovechen los trabajos de extensión en el enriquecimiento de la actividad docente y universitaria. 
3. Los programas nacionales de apoyo al desarrollo de la cultura y de las artes deberían crear fondos especiales concursables para que las universidades propongan actividades en las que presenten fortalezas y experiencias institucionales. Por lo general, las instituciones de educación superior deben competir en los concursos junto a instituciones $u$ organizaciones de otro tipo, lo que puede perjudicar a unos $\mathrm{u}$ otros por la distinta naturaleza de su competencia.

4. Las universidades regionales deberían evaluar y analizar sus fortalezas y su acervo cultural, con el fin de diseñar estrategias de desarrollo en las que asignen recursos discrecionales para áreas de mayor idoneidad y para el fortalecimiento de áreas deficitarias o inexistentes, y cuya presencia activa es requerida por la comunidad.

5. Se recomienda crear fuertes vínculos entre las actividades de extensión y la docencia, especialmente en los programas de pregrado, con el fin de aportar al desarrollo humano, cultural y social de los futuros profesionales. Se constatan serias deficiencias en algunas profesiones. Los ingenieros, por ejemplo, necesitan desarrollar su imaginación creadora y para ello es importante que dediquen una parte de su tiempo al ejercicio de expresiones artísticas.

6. Los gobiernos regionales deberían fortalecer las actividades culturales, artísticas y sociales de los programas de extensión universitaria, apoyo que se ha visto aparecer en el marco de las actividades realizadas por el Programa Universidades-Gobiernos Regionales, de la Subsecretaría de Desarrollo Regional entre 1995 y 2002. Estos apoyos deberían consolidarse en proyectos conjuntos de valorización del patrimonio regional, especialmente monumentos, historia regional, culturas y artes originarios, tales como folclore, artesanía y otros.

7. Es necesario que las universidades regionales, especialmente las estatales, concierten programas conjuntos de desarrollo de la extensión, especialmente en macrorregiones del país, aprovechando la similitud de sus recursos o de sus patrimonios históricos, étnicos o artísticos. 